\title{
Uruguay: cómo nos cambia la vida
}

\author{
Rodolfo Schmal S. \\ Universidad de Talca, Talca, Chile. Email: rschmal@utalca.cl
}

\begin{abstract}
Resumen: La evolución política latinoamericana, particularmente en el cono sur -Uruguay, Chile y Argentina- en los últimos 50 años ha experimentado cambios significativos, desde los tiempos en que los formalismos democráticos eran puestos a prueba por crisis económicas y sociales que desembocaban en crisis políticas, las que por lo general terminaban "resolviéndose” por la vía militar. Agotada esta instancia, los países han tendido a retomar los cauces democráticos. Hoy nos encontramos inmersos en la oleada transicional hacia la democracia. En este artículo se aborda la evolución de un país, la República Oriental del Uruguay, en razón a las particulares características que ha asumido y cuyo rasgo más visible es el ascenso a la cúspide del poder político, la Presidencia de la República, de quien hace menos de 50 años fuera guerrillero, por la vía electoral.
\end{abstract}

Palabras clave: política, democracia, transición.

\section{Uruguay: how life changes us}

\begin{abstract}
The latinamerican political evolution, particularly in the southern cone-Uruguay, Chile and Argentina- in the last 50 years has undergone significant changes, since the time when the democratic formalisms were tested by economic and social crisis ending into political crisis, which usually ended being "solved" by military coups. Once exhausting this instalation, countries have returned to the democratic system. Today we are surfing inside transitional waves towards democracy. This article presents the evolution of a country, the Oriental Republic of Uruguay, due to certain specific characteristics, being the most visible one the rise to the highest political position, the Nations Presidency, through elections, of a man who less than 50 years ago was part to the guerrilla warfare.
\end{abstract}

Key words: polítics, democracy, transition

\section{Uruguai: como a vida nos muda}

Resumo: A evolução política latinoamericana, particularmente no Cone Sul, Uruguai, Chile e Argentina nos últimos 50 anos passou por mudanças significativas desde o momento em que as formalidades democráticas foram testados pela crise econômica e social, que fluiu em crise política, eles geralmente acabam por "resolvido" por meios militares. Esgotada esta instância, os países tendem a retornar à democracia. Hoje, estamos imersos na onda de transição para a democracia. Este artigo discute a evolução de um país, a República Oriental do Uruguai, devido às características particulares e que assumiu a característica mais visível é a subida ao cume do poder político, a Presidência da República através de eleições, , do quem faz menos de 50 anos fora da guerrilha

Palavras-chave: política, democracia, transição 


\section{Introducción}

El reciente ascenso a la presidencia del Uruguay de José Mujica, alias Pepe, quien fuera un guerrillero en la década de los 60 , constituye un hecho que invita a preguntarse acerca de las circunstancias que lo hicieron posible. $\mathrm{Y}$ al intentar buscar estas circunstancias, inevitablemente debemos retroceder en el tiempo. Poco sirve afirmar que Uruguay es un país especial, con características singulares, porque también posee características que nos son comunes. Y al intentar desentrañar los misterios o factores que pudieran explicar el desenlace de la reciente elección presidencial uruguaya, inevitablemente asoman personajes, hechos, atributos, realidades que en su conjunto, nos puedan ayudar a encontrar respuesta a la interrogante clave: ¿cómo fue posible que Pepe llegara a ser presidente?

Las realidades políticas en las distintas décadas han tenido su propio sello: la década de los 60 está marcada por el influjo de la revolución cubana y una crisis política in crescendo que desemboca en la década de los 70 con las sucesivas dictaduras civiles y militares. Todo esto en línea con lo que ocurre en el continente, cuyas frágiles democracias están dominadas por caudillismos allí donde la institucionalidad política era débil, o sobrepasadas por demandas que la oligarquía no estaba dispuesta o eran incapaces de atender. A la oleada militarista de los 70 le sucede en los 80 la fiebre de las transiciones hacia la democracia. Los "señores políticos" denostados por quienes habían asumido la conducción política de los países, resucitan en gloria y majestad. Es así como se llega a la década de los 90, con los militares batiéndose en retirada y los políticos volviendo por sus fueros.

Con el amanecer del nuevo siglo en algunos países este proceso parece consolidarse y en otros debilitándose. Unos miran hacia la izquierda, otros hacia la derecha, y también están quienes se ven tentados por recorrer sendas difíciles de identificar.

\section{Antecedentes generales}

Hasta la década de los 60, la izquierda en Uruguay se caracterizó por encontrarse disgregada, atomizada. El primer esfuerzo por reunir las fuerzas de izquierda se produce en 1961 cuando se estructura el Frente de Izquierda de Liberación (FIDEL) bajo el influjo de la revolución cubana. En un contexto de guerra fría a nivel mundial, el protagonismo del partido comunista uruguayo (PCU) en FIDEL limitaba las posibilidades electorales de la izquierda en un cuadro político dominado por los partidos tradicionales uruguayos: el partido colorado y el partido blanco.

A fines de los 60, al igual que en otros países latinoamericanos, en Uruguay surge un movimiento guerrillero, los tupamaros, alias tupas, quienes dan por clausuradas las posibilidades de acceso al poder político por la 
vía electoral, optando por la vía armada. El cuadro político, económico y social, de por sí ya complejo, se agrava, restando espacios a la negociación y abriendo cancha a la militarización de la política. El gobierno civil colorado encabezado por Pacheco Areco, un oscuro personaje sin mayor figuración política al momento de asumir al fallecer el presidente en ejercicio, General Gestido, resuelve abolir las garantías constitucionales en el año 1971. Con Pacheco Areco se da inicio al período militar, que en Uruguay tuvo como principales protagonistas al propio Pacheco Areco, a José María Bordaberry y al General Gregorio Alvarez. Los dos primeros, del partido colorado, el mismo de José Batlle y Ordoñez, verdadera leyenda de comienzos del siglo pasado y cuyo legado se disputan no solo distintas facciones del propio partido colorado, sino que de otros grupos políticos, incluyendo aquellos pertenecientes al propio FA.

Si bien la izquierda emerge desde mediados del siglo pasado, su presencia es marginal, y solo cobra fuerza a partir de los años 70 , con el FA, e inicia su consolidación participando en las negociaciones por el término de la dictadura en la década de los 80 . Este proceso de consolidación encuentra su punto culminante en la elección del primer gobierno de izquierda en el 2004 al lograr el triunfo de su abanderado presidencial, un oncólogo socialista, de carácter afable, moderado, Tabaré Vázquez.

No obstante que a los partidos colorado y blanco se les asocia con la derecha, los primeros vinculados a intereses capitalistas urbanos y los segundos a los intereses de los grandes hacendados en el campo, en ambos siempre han coexistido corrientes internas que no siempre son plenamente asimilables a la derecha. De hecho, particularmente el partido colorado ha contado en su seno con componentes extremos tanto hacia la derecha -en primera línea destacan Pacheco Areco y Bordaberry, ambos acérrimos anticomunistas- como hacia la izquierda -Hugo Batalla y Zelmar Michelini entre otros-.

Por tanto, para explicar el proceso por el cual Pepe Mujica llega a la presidencia necesariamente nos obliga a repasar a algunos de los personajes arriba mencionados, algunos hitos tales como el pacto del puerto de Buceo, la ley de lemas, las internas, los plebiscitos, en una realidad uruguaya marcada por su baja población, fuerte emigración de los más jóvenes, la alta proporción de adultos mayores, su posición geográfica.

\section{Los inicios del Frente Amplio}

El General Liber Seregni (Caetano, 2005) es un personaje clave para entender la evolución de una izquierda uruguaya que estaba monopolizada por el partido comunista. La izquierda en Uruguay estaba centrada en el partido comunista y el partido socialista (PS), sin desmerecer la existencia de múltiples grupos o grupúsculos anarquistas, troskistas, obreristas, fragmentados, que a lo más se habían logrado fusionar en los inicios de los años 60 por influencia de la revolución en torno a lo que se denominó Frente de 
Izquierda de Liberación (FIDEL) y la llamada Unión Popular, que si bien como expresión electoral no alcanzaron mayor peso, fue un primer intento de agrupación de la izquierda. Sin embargo sus proyecciones eran limitadas por girar uno en torno al PCU y el otro al PS. Desde la izquierda existían fuerzas que privilegiaban el camino electoral y aquellas que privilegiaban la opción armada, coexistencia nunca bien resuelta y siempre bien aprovechada por las fuerzas políticas de derecha, esto es, los partidos tradicionales, el colorado y el blanco. El dominio de estos partidos solo logró ser amagado en las elecciones que se dieron desde los 90 .

Este paralelismo entre el camino electoral privilegiado por unos -particularmente el PCU- y el armado por otros -en especial los tupamaros-, marcó fuertemente a la izquierda uruguaya- esto en medio de un agotamiento del modelo político económico social uruguayo producto de una radicalización de las contradicciones del sistema capitalista en el Uruguay que imposibilitaban continuar financiando un país donde la presencia del Estado no era marginal. El Estado había desempeñado un papel crucial en la construcción del Uruguay tal como se le conocía -con una educación y una salud pública y gratuita de calidad-. En este contexto se funda en 1971 el Frente Amplio (FA) como una coalición formada por los partidos socialista, comunista y demócratacristiano, además de sectores escindidos del partido colorado y del partido nacional. El FA surge en una coyuntura de crisis política-económica-social como sucesor de FIDEL y la Unión Popular, pero con una capacidad de convocatoria más amplia, no monopolizada por el PCU, y que desde el primer minuto es conducido por el General Líber Seregni, ya bajo el gobierno de Pacheco Areco, quien había asumido la presidencia en 1967 ante la muerte del entonces presidente constitucional, el General Gestido. En su primera intervención pública como presidente del FA, el 26 de marzo de 1971, Seregni afirma:

¿Cómo no van a agudizarse las tensiones sociales? ¿Es que alguien puede creer que con Medidas Prontas de Seguridad, con un estado policial, va a solucionarse la inseguridad que hoy afecta a todo el país, la inseguridad de los productores y de los trabajadores? Porque la nuestra es una inseguridad global, que afecta a todos los ámbitos de la vida. Se limitan las libertades públicas, desaparece la libertad de prensa, ocurren encarcelamientos masivos sin justificación alguna, se ataca con ensañamiento a la enseñanza tanto a nivel universitario como secundario.

Más adelante, en la misma ocasión, Seregni planteaba la disyuntiva bajo la cual se encontraba Uruguay entonces:

La disyuntiva de hoy es muy clara: o la oligarquía liquida al pueblo oriental, o el pueblo oriental termina con la oligarquía. Esa es la radicalización política de hoy; ésa es la expresión de la realidad que vivimos: un país empobrecido y empobreciéndose no puede seguir con soluciones de medias tintas. 
Y Seregni, en representación del FA, denuncia:

Entonces fue la oligarquía la que resolvió radicalizarse, la que quiso terminar con las “medias tintas”, porque únicamente podía mantenerse transfiriendo lodo el peso de la crisis sobre el pueblo. Así vino el gobierno del Señor Pacheco y las Medidas de Seguridad como un régimen permanente. Y vinieron los últimos tiempos. Los políticos blancos y los políticos colorados quedaron relegados y la oligarquía tomó directamente el gobierno. Esto nunca había sido tan visible, tan descarnado y tan claro. Los grupos económicamente dominantes estaban dispuestos a todo para reducir al pueblo oriental y se abrió así una era de violencia, la que estamos viviendo. La violencia comenzó desde arriba. La estructura de dominación oligárquica quedó al desnudo; decretó que era la "hora del garrote” y, como siempre, cínicamente, culpó del desorden a las masas estudiantiles y a las masas obreras.

En consecuencia, al nacer el FA, sus postulados se centran en su oposición a la oligarquía, al conculcamiento de las libertades públicas, recogiendo el creciente descontento, particularmente entre los jóvenes, los intelectuales, residentes urbanos y de importantes sectores medios de la sociedad uruguaya. Lo más significativo reside en que la aparición del FA es la primera iniciativa con posibilidades serias de poner en jaque un sistema bipartidista que desde el nacimiento del Uruguay como nación monopolizaba las preferencias de alrededor del 90\% de los padrón electoral.

Desde su nacimiento, el FA inicia una senda ascendente tras cada elección presidencial, la que encuentra su punto culminante en las elecciones presidenciales del 2004 cuando por primera vez gana el gobierno en primera vuelta como se observa en la tabla. Obsérvese que ya en 1971, el mismo año de su nacimiento, el FA rompe el bipartidismo cuando su abanderado, Liber Seregni logra un 18\% contra poco más del $40 \%$ que obtienen cada uno de los partidos tradicionales, el colorado y el blanco o nacional. Estas elecciones están caracterizadas por las denuncias de fraude del candidato blanco Wilson Ferreira contra el candidato colorado, Juan María Bordaberry, quien fue proclamado ganador en medio de claras irregularidades, y por el crecimiento de la izquierda que en el pasado no superaba el $10 \%$ de la votación total. El 18\% alcanzado por el FA adquiere mayor relevancia al tomar en consideración que se da en un contexto de un creciente distanciamiento entre la izquierda tradicional, ortodoxa, monopolizada por el PCU, que privilegiaba la vía electoral para acceder al poder, y quienes impulsaban la vía armada disgregados en múltiples grupos. De estos, por la envergadura y espectacularidad de sus operativos, los que incluían asaltos y secuestros, destacaron los tupamaros liderados por Raúl Sendic (Blixen, 2000). 


\begin{tabular}{|l|c|c|c|c|c|c|c|}
\hline & $\mathbf{1 9 7 1}$ & $\mathbf{1 9 8 4}$ & $\mathbf{1 9 8 9}$ & $\mathbf{1 9 9 4}$ & $\mathbf{1 9 9 9}$ & $\mathbf{2 0 0 4}$ & $\mathbf{2 0 0 9}$ \\
\hline Partido Colorado & $41 \%$ & $41 \%$ & $30 \%$ & $32 \%$ & $33 \%$ & $11 \%$ & $17 \%$ \\
\hline Partido Nacional & $40 \%$ & $35 \%$ & $39 \%$ & $31 \%$ & $22 \%$ & $35 \%$ & $29 \%$ \\
\hline Frente Amplio & $18 \%$ & $21 \%$ & $21 \%$ & $31 \%$ & $40 \%$ & $52 \%$ & $48 \%$ \\
\hline Otros & $1 \%$ & $3 \%$ & $10 \%$ & $6 \%$ & $5 \%$ & $2 \%$ & $3 \%$ \\
\hline Total & $100 \%$ & $100 \%$ & $100 \%$ & $100 \%$ & $100 \%$ & $100 \%$ & $100 \%$ \\
\hline
\end{tabular}

Fuente: Corte Electoral del Uruguay

\section{Los años de la represión}

Pacheco Areco no lo dudó: en vez de enfrentar los problemas reales subyacentes en la galopante crisis que estaba desembocando en una sangría emigratoria de los mejores hijos(as) del Uruguay, resuelve emprender medidas de carácter represivas, aún contra la voluntad de importantes sectores de su propio partido, el colorado.

A poco andar, de la mano de Pacheco Areco, el gobierno resuelve reprimir la efervescencia social y la guerrilla desencadenada fundamentalmente por el Movimiento de Liberación Popular (MPL), más conocidos como los tupamaros, mediante la aplicación de las llamadas medidas prontas de seguridad que le permitían combatir la "sedición" con "mayor eficacia”; los problemas económicos los abordó con las clásicas políticas de shock, que incluyeron congelamientos salariales en contextos inflacionarios.

Con Bordaberry en la presidencia desde 1972, el proceso de deterioro económico-social continúa agudizándose, al igual que la represión y la lucha contra la guerrilla. Los máximos dirigentes de los grupos guerrilleros, que ya se encontraban en la clandestinidad, son detenidos en 1972, acusados de sedición y permanecen recluidos y sometidos a incomunicación y torturas. Entre ellos destaca quien hoy es presidente del Uruguay, Pepe Mujica ${ }^{1}$.

Bordaberry, para enfrentar la galopante crisis de todo orden que se vivía en 1973, solo atina a dar un golpe y disolver el poder legislativo constituido por las cámaras de senadores y representantes. Se justifica sobre la base de que:

la realidad político-institucional del país demuestra un paulatino, aunque cierto y grave, desconocimiento de las normas constitucionales (...) es que la acción delictiva de la conspiración contra la Patria, coaligada con la complacencia de grupos políticos sin sentido nacional se halla inserta en las propias instituciones para así presentarse encubierta como una actividad formalmente legal. 
Además, Bordaberry suprime las escasas libertades aún vigentes, al establecer la censura de los distintos medios de comunicación:

la divulgación por la prensa oral, escrita o televisada de todo tipo de información, comentario o grabación que, directa o indirectamente, mencione o se refiera a lo dispuesto por el decreto atribuyendo propósitos dictatoriales al Poder Ejecutivo o pueda perturbar la tranquilidad y el orden público.

En el año 1976 Bordaberry es destituido por las Fuerzas Armadas luego que estas rechazaran una propuesta que realizara y en la que pretendía asumir mayores poderes de los que ya tenía. En consecuencia, las FFAA uruguayas resuelven sustituirlo por Demichelli en primera instancia, y luego, en el mismo año, por Mendez, ambos dirigidos por control remoto por las cúpulas militares renuentes a asumir directamente el mando de la nación. Esta actuación tras las bambalinas por parte de las FFAA se explica por la tradición civilista, republicana del Uruguay. En 1980 los uruguayos son convocados a un plebiscito para pronunciarse en torno a una reforma constitucional (Corbo, 2006), cuyo objetivo no era otro que perpetuar la presencia militar en el gobierno. Aún cuando este plebiscito se llevó a cabo con los principales dirigentes políticos proscritos, el rechazo a la propuesta de la dictadura fue claro y categórico, obligándola a emprender un lento proceso de retorno a las habituales reglas del juego democrático ${ }^{2}$.

Por esos años, tanto en Uruguay, como en Chile y Argentina, existía un común denominador dado por dictaduras interrelacionadas que obedecían a una misma doctrina de seguridad interior del Estado aplicada por las respectivas FFAA mediante políticas terroristas al amparo del Estado que tuvieron un carácter sistemático y planificado, estando las personas con sus derechos ciudadanos conculcados. La comunicación, traspaso de información y ejecución de las decisiones asociadas a estas políticas se desarrolló en el marco de la denominada Operación Cóndor. Entre las tantas víctimas que pagaron cara su consecuencia, destacan Zelmar Michelini y Héctor Gutierrez, políticos uruguayos que provenían de los partidos tradicionales y que habían sido expulsados del país. Posteriormente fueron secuestrados y asesinados en 1976 en la ciudad de Buenos Aires por orden del gobierno uruguayo presidido por Bordaberry. Por este hecho, tanto Bordaberry como su canciller, Juan Carlos Blanco, han sido procesados y recientemente condenados. Otro alto destacado dirigente de uno de los partidos tradicionales, el blanco, Wilson Ferreira, logró escapar antes que un escuadrón lo secuestrara, forzándolo a exiliarse a Europa (Lessa, 2003).

En 1981 las FFAA resuelven asumir la conducción directa del Estado sin mediación civil, vía el general Gregorio Alvarez. El resultado del plebiscito de 1980 le obligó a iniciar conversaciones con las dirigencias partidarias encaminadas a la normalización democrática. A estas alturas la guerrilla había sido diezmada como consecuencia de la represión desencadenada contra ella, no así la izquierda que emerge intacta y con nuevos bríos. 


\section{Las negociaciones}

En 1984 tiene lugar el denominado Pacto del Club Naval, todo un hito en el proceso de normalización institucional que no estuvo exento de tensiones por la existencia de partidos y dirigentes políticos proscritos por la dictadura, y la disposición de otros dirigentes a participar en las negociaciones que se estaban convocando. La fuerza de la dirigencia política residía en la existencia de un inocultable descontento popular ante la situación económica que se vivía y expresada en multitudinarias manifestaciones y caceroladas, además de contar con el respaldo del resultado plebiscitario del 80 de rechazo a las pretensiones de perpetuación de la dictadura. Estaban quienes deseaban aprovechar la oportunidad de normalización bajo las condiciones imperantes, y aquellos otros que no estaban disponibles para hacerlo mientras existieran partidos y dirigentes políticos proscritos. Acceden a conversar el partido colorado, el FA y la Unión Cívica (Demócrata Cristiano); el partido blanco resuelve no participar. Resulta curioso constatar la ausencia de uno de los partidos tradicionales, el blanco, y la presencia del FA, lo que da cuenta del pragmatismo que estaba empezando a apoderarse del FA y/o el impacto que la represión había generado en sus filas. Cuando su líder máximo, Liber Seregni fue liberado en 1984 tras 10 años de prisión, desde el balcón de su apartamento entregó un mensaje sereno, escuchado con profunda emoción por sus adherentes, y en el que invitaba a la paz, a la reconciliación nacional y exigía la inmediata liberación de todos los presos políticos.

Antes que ustedes se retiren, quiero decirles una cosa, la gran preocupación de este momento, para poder transitar efectivamente los caminos a la recuperación de la democracia es la pacificación de los espíritus, la pacificación nacional. Lo sentimos como la necesidad, no hay democracia si no hay paz. Y la pacificación que lleve al reencuentro de los orientales tiene que reconocer necesariamente la más amplia de las amnistías, la libertad de los presos políticos, el retorno de los exiliados, la desproscripción de hombres y partidos.

Así como el plebiscito marcó el inicio del fin de la dictadura, el pacto del club naval marcó su fin propiamente tal y las características que tendría la transición uruguaya: el corrimiento hacia el centro no tanto de la izquierda, como de la ultraizquierda, representada mayoritariamente por quienes fueron tupamaros (Gilio, 2010).

Desde los dirigentes tupamaros y de otros grupúsculos que habían optado por la vía armada y que se encontraban en el exilio o encarcelados, surge un proceso de reflexión que los conduce a insertarse en la vía electoral, y por lo general a engrosar las filas del FA. Los tupamaros de entonces dan forma al Movimiento de Participación Popular (MPP), que en forma paulatina van incrementando su peso dentro de la coalición frenteamplista. Es así como hoy uno de los suyos es presidente del Uruguay. Como anécdota cabe destacar que el actual ministro del Interior, Eduardo Bonomi, y como tal responsable de la seguridad ciudadana y que tiene a su cargo a la 
policía nacional, fue un destacado dirigente tupamaro que estuvo en la clandestinidad y encarcelado por los militares. Y como ministro de Defensa Nacional, Pepe Mujica nombró a Luis Rosadilla, otro destacado militante tupamaro desde sus tiempos mozos, y que perdió su libertad en 1973, la que recuperó solo en 1982. Estos son solo dos ejemplos, verdaderamente macondianos, surrealistas, que dan cuenta de algo inédito: un país que está siendo conducido por un ex tupa, cuyas fuerzas policiales son dirigidas por otro ex tupa, y cuyas FFAA están subordinadas por otro ex tupa. Nadie se lo hubiese imaginado.

\section{La transición democrática}

Las primeras elecciones democráticas bajo la dictadura, en 1984, dan el triunfo al partido colorado, liderado por José María Sanguinetti, quien fue uno de los actores claves participantes del pacto del club naval. Al asumir en 1985 marca el término de la dictadura al liberar a todos los presos políticos, entre ellos, el actual presidente del Uruguay. Con Sanguinetti se inicia la transición propiamente tal. En una decisión que hasta nuestros días ha sido resistida, en 1986 dicta la ley de caducidad que busca blanquear los delitos cometidos durante la dictadura bajo el argumento de la necesidad de alcanzar la reconciliación entre los uruguayos. Esta ley beneficiaba particularmente a los miembros de las FFAA y civiles que habían cometido delitos en el marco del terrorismo de Estado imperante. La resistencia a esta ley se expresó en dos intentos por derogar dicha ley. En ambos casos, si bien se obtuvo el número de firmas para convocar a plebiscito, cuando éste tuvo lugar, la mayoría optó por no derogarla. En determinados sectores se cree que la ley de caducidad fue una imposición no escrita del pacto del club naval.

Con Sanguinetti no solo se inicia la transición uruguaya, sino una sucesión de gobiernos de los partidos tradicionales que durará 20 años, de 1985 hasta 2005, así como en Chile la Concertación gobernó 20 años en Chile, con un desfase de 5 años ${ }^{3}$.

En pleno período de transición democrática, y bajo el tercer gobierno democrático posdictadura, el segundo encabezado por Sanguinetti, se promulga la Constitución de 1997 luego de un largo período de desacuerdos (Piñeiro, 2007; Buquet, 2009). Ésta contiene importantes disposiciones que alterarían el comportamiento futuro de los actores políticos y ciudadanos. En el ámbito electoral, para los efectos de la elección presidencial, las modificaciones más sustantivas se relacionan con la exigencia de candidatos únicos por partido y la introducción del balotaje o segunda vuelta en caso que ninguno de los candidatos obtenga la mayoría absoluta en la primera vuelta. En su momento esta última disposición se visualizó como un obstáculo para el acceso del FA al gobierno, dado que se estimaba que para el FA superar el 50\% era una barrera insalvable dado que se presumía que las fuerzas de los partidos tradicionales se unirían contra el FA. 
Y así ocurrió en las primeras elecciones posteriores de 1999, donde Tabaré Vázquez (FA) obtuvo un $40 \%$ de los votos, por encima del 33\% de Jorge Batlle (PC), pero en el balotaje este último triunfó gracias al respaldo del candidato blanco. Sin embargo, la intención de voto a favor del FA seguía una tendencia al alza difícil de contrarrestar que más temprano que tarde posibilitaría el acceso a la presidencia por parte del FA. La velocidad de este proceso se vio facilitada por la crisis económica vivida por el Uruguay en el 2002 bajo el gobierno de Batlle. Así se llega al 2004, donde Tabaré gana en primera vuelta sin necesidad de balotaje alguno al lograr sobre el $50 \%$ de las preferencias ciudadanas.

Un factor que dificultaba el ascenso del FA residía en las características del sistema electoral uruguayo que posibilitaba que un mismo partido presentara más de un candidato a la presidencia. Los votos de los candidatos de un mismo partido se sumaban y el candidato electo era aquel más votado dentro de la lista partidaria más votada. Los partidos tradicionales normalmente estaban organizados en corrientes, cada uno con sus respectivos líderes. Por otra parte, estas corrientes, en términos ideológicos podían reconocer aguas desde la izquierda hasta la ultraderecha. A modo de ejemplo, tanto dentro del partido colorado como blanco era posible localizar sectores claramente anticomunistas y reconocidamente fascistas, que convivían con sectores progresistas dentro de sus respectivos partidos. Solo de esta forma logra explicarse que la dictadura existente entre 1973 y 1985 haya contado tanto con el respaldo y protagonismo de significativos sectores de los partidos tradicionales, como con la resuelta oposición de otros sectores de los mismos partidos. Para la dictadura estos sectores llegaron a ser considerados enemigos de la patria, lo que los condenaba a ser candidatos a ser secuestrados y asesinados por escuadrones de la muerte financiados y amparados por el aparato del Estado, como fue el caso de Zelmar Michelini y Héctor Gutierrez, o proscritos o exiliados, como fue el caso de Wilson Ferreira. Con el tiempo, estos sectores de izquierda dentro de los partidos tradicionales han ido perdiendo peso por su tendencia a migrar hacia el FA, lo que es causa y efecto de la moderación que esta coalición ha ido experimentando, amén de la metamorfosis vivida por quienes provienen de la izquierda más ortodoxa y quienes en algún momento empuñaron las armas en su pretensión de cambiar la sociedad.

La exigencia de candidatos únicos por partido en un país en el que históricamente cada partido podía presentar más de un candidato instituyó el esquema de las elecciones internas, las que tienen carácter de obligatorias y deben ser realizadas simultáneamente ${ }^{4}$. Debido a que en el seno de los partidos tradicionales coexistían posturas sin mayor afinidad ideológica -convivían sectores progresistas con sectores retrógrados-, esta disposición se asume que debe tender a homogeneizar el conjunto de ideas de los adherentes de un mismo partido y diferenciar más nítidamente a los que se encuentran en distintas tiendas partidarias. En la actualidad pareciera que los partidos están en pleno proceso de posicionamiento dentro del espectro ideológico. 


\section{El primer gobierno del FA}

$\mathrm{Al}$ asumir Tabaré la conducción del primer gobierno del FA5, Uruguay hizo historia al romper el monopolio ejercido por los partidos tradicionales desde los albores de la república (Queirolo, 2006). Asume en condiciones de crisis expresada en una pesada deuda externa de más de 12 mil millones de dólares y una tasa de desempleo por sobre el $10 \%$. Tabaré, al asumir el mando de la nación contrae un conjunto de compromisos definidos en su programa de gobierno, expresando

Prometimos cambios y haremos cambios. Empezando por el gobierno mismo, en su actitud, en sus acciones, fundamentalmente en lo que se refiere a la austeridad, el respeto, el diálogo, la tolerancia y la modalidad de trabajo cotidiano.

Cambios impostergables; cambios factibles; cambios responsables; cambios progresivos; cambios entre todos y para todos, pero especialmente en beneficio de quienes más los necesitan para alcanzar niveles de vida digna.

En el mismo discurso, Tabaré también se dirigió al más de un millón de uruguayos que viven en el exterior, pero que siguen pensando en su tierra patria. Y recordando a Artigas, referente ineludible de todo uruguayo, sostuvo

José Artigas fue uno de ellos. Traicionado y derrotado en 1820, vivió exiliado en nuestra hermana República del Paraguay, hasta su muerte en 1850. En cierta forma ese exilio fue una larga agonía, una crucifixión de 30 años que Artigas soportó en silencio, sin un lamento, sin un reproche.

Cuenta la historia que alguien fue a visitarlo atraído por su pasado como Jefe del Pueblo Oriental y Protector de los Pueblos Libres. Al recibirlo, el viejo General le preguntó con una mezcla de tristeza y picardía: “¿ ...Así que mi nombre todavía suena por allá....?

Seregni, el lider fundador del FA y que lo presidió por 25 años, prisionero de la dictadura por más de una década, no alcanzó a ver el fruto de su prédica constante y pertinaz. En el homenaje que se le rindió a un año de su fallecimiento, con Tabaré ya instalado en el gobierno, su ministro de Educación y presidente en ejercicio del FA destacó su

Ejemplo de conducción, ante todas las adversidades, de un proyecto político que probablemente nunca se hubiera consumado sin esa conducción, en la que hizo gala de perspicacia, equilibrio, inventiva, paciencia, capacidad de comunicación, instinto del momento político, sentido del ritmo histórico; y, sobre todo, debemos destacarlo, una y otra vez, de grandeza intelectual y moral. 
Y no solo contribuyó a la consumación del proyecto, sino que lo llevó paso a paso, en las peores condiciones que un movimiento político uruguayo haya padecido, a las puertas de la victoria, que él también traspuso y cuya gloria llegó a saborear.

El gobierno de Tabaré no estuvo exento de dificultades y contradicciones. Al igual que en otras transiciones encabezadas por coaliciones de centroizquierda, la iniciativa en relación al modelo económico y la inserción internacional fue asumida desde un comienzo por quienes impulsaban profundizar el modelo de mercado, atraer inversiones extranjeras y abrir la economía hacia el mundo; quienes dentro del FA se resistieron, y resisten a esta estrategia, carecían de una propuesta alternativa común. No obstante ello, Tabaré logró sortear dificultades, revertir el proceso de deterioro que vivía Uruguay, reducir el desempleo y generar un nuevo estado de ánimo, más optimista que pesimista, no habitual en el ser uruguayo. Lo paradojal reside en que se aplicaron medidas laborales progresistas conducentes a promover la organización sindical y reducir las asimetrías del trabajo con respecto al capital, que en cierta forma perturban a quienes conforman el equipo económico de gobierno. No obstante lo expuesto, al término de su gobierno Tabaré obtiene un respaldo ciudadano superior al 60\%, inédito en la historia política uruguaya.

Para las elecciones del 2009 el favorito de Tabaré para su sucesión fue Astori, quien como ministro de Economía fue el responsable de un manejo ortodoxo de la economía. Sin embargo la interna del FA dijo otra cosa, desafiando el liderazgo de Tabaré y escogiendo a Pepe Mujica como candidato único del FA. Importa destacar que el FA normalmente designaba a su candidato presidencial en asambleas partidarias y los liderazgos eran indiscutibles. Primero lo fue Liber Seregni, y luego Tabaré Vázquez, quienes lideraron las listas del FA sin mayores discusiones internas. Distinto fue el caso en esta ocasión. La inobjetable victoria de Pepe en las internas, y el inmediato acompañamiento de Astori en la fórmula presidencial despejaron el panorama, aunque se temía que la personalidad e historia de vida de Pepe dificultara el triunfo electoral ${ }^{6}$. De hecho así fue, puesto que Pepe no pudo proclamarse presidente electo en la primera vuelta por no alcanzar al menos el 50\% de los votos válidamente emitidos. A pesar que colorados y blancos unieron fuerzas para derrotarlo en la segunda vuelta, Pepe logró superar a Lacalle, su contrincante blanco ${ }^{7}$.

\section{El triunfo de Pepe}

Mujica, alias Pepe, tiene 74 años, chacrero, extupamaro, de la izquierda extramuros, la ultraizquierda, la terrorista, participante en asaltos a mano armada en la década de los 60, estuvo encarcelado por más de 10 años y fue torturado bajo la dictadura. Hoy un tipo con pinta de abuelo, bonachón, socarrón (Gilio, 2010). Cuesta encontrar en la historia política de los países un ejemplo similar. Con tan solo 5 años en el gobierno, la centroizquierda, representada por el FA apostó a un salto hacia delante. 
El pueblo uruguayo apostó por él, quien nos habla en lenguaje cotidiano, por cuya humanidad ha pasado mucha agua, como por todos nosotros. Entre sus frases para el bronce se encuentra aquella que dice: "Yo antes aspiraba a cambiar el mundo. Ahora, la vereda de mi casa". Una frase que para muchos refleja evolución, madurez, pragmatismo, realismo, sensatez, sin por ello, perder la brújula; para otros revela traición. Un presidente que en Punta del Este, balneario del jet set rioplatense, recientemente "encandiló" a mas de 1000 empresarios al reiterarles lo que ya sostuviera en esa misma localidad hace ya casi medio siglo otro guerrillero, el Ché Guevara: que la vida económica debe estar supeditada a la política, y no al revés. La diferencia residió en que Pepe no vino a confrontar, sino que a conversar. Afirmó que los uruguayos "necesitamos inversión, porque se necesita más y cada vez mejor trabajo", y por otra parte sostuvo que "la riqueza es hija del trabajo y el trabajo necesita inversión.... No somos Mandrake, no podemos generar riqueza (solo) con decisiones legislativas” (Cafassi, 2010).

En su primer discurso como presidente, ante la asamblea legislativa, da cuenta de la transformación experimentada por un guerrero convertido en un hombre de paz.

Me estoy imaginando el proceso político que viene, como una serie de encuentros, a los que unos llevamos tornillos y otros llevan las tuercas. Es decir, encuentros a los que todos concurrimos con la actitud de quien está incompleto sin la otra parte.

En ese tono se va a desarrollar el próximo gobierno del FA.

Asistiendo incansablemente a las mesas de negociación con vocación de acuerdo. Puede ser que el gobierno tenga más tornillos que nadie, más tornillos que el partido nacional, más que el partido colorado, más que los empresarios y más que los sindicatos....

¿Pero de qué nos sirven los tornillos sueltos, si son incapaces de encontrar sus piezas complementarias en la sociedad?

Vamos a buscar así el diálogo, no de buenos, ni de mansos, sino porque creemos que esta idea de la complementariedad de las piezas sociales, es la que mejor se ajusta a la realidad.

Nos parece que el diagnóstico de concertación y convergencia es más correcto que el de conflicto, y que sólo con el diagnostico correcto se puede encontrar el tratamiento correcto.

Sin embargo, esta lectura, también tiene otras, particularmente de aquellos compañeros de ruta de los años 60 que se resisten a "renovarse o reciclarse"; son quienes los acusan de renegados de izquierda que se han pasado a las fuerzas del capitalismo; de ser neoliberales o socialdemócratas que han abjurado de la revolución y el socialismo, y 
que pertenecen a las más diversas variantes del oportunismo y del travestismo.

En este exguerrillero, y otros que lo secundan, han confiado los uruguayos los destinos de una nación envejecida, con baja tasa de natalidad y cuyos mejores hijos tienden a buscar nuevos horizontes más allá de sus fronteras.

\section{Conclusiones}

Este crecimiento del FA se ha intentado explicar tanto por causas demográficas, ideológicas y económicas (Queirolo, 2006). Las demográficas tiene que ver con que desde su origen el FA atrajo a los jóvenes votantes, que suelen caracterizarse por su menor aversión al riesgo, y en 1971 el FA era una fuerza política emergente, denunciante, crítica de la realidad imperante, pero sin experiencia en tareas de gobierno. Posteriormente, desde las elecciones de 1981, el FA sigue contando con los votos de quienes ya no son jóvenes, pero que en su juventud votaron por el FA, y continúa conquistando votos en dicho segmento. Por tanto logra continuar atrayendo a los jóvenes sin dejar de cautivar a los ya no tan jóvenes. Las causas ideológicas están asociadas a la moderación discursiva, al desmarque del marxismo en un país con una importante población proclive a recoger el mensaje anticomunista. El liderazgo de su creador, Líber Seregni, contribuyó con mucha fuerza a este corrimiento hacia el centro, apelando a las ideas del prócer uruguayo, José Gervasio Artigas, como se testimonia en su primer discurso como líder de la agrupación en 1971.

El Frente Amplio es heredero de la tradición artiguista. Es por esto que el Frente Amplio no es una simple suma de partidos y de grupos; es la nueva conciencia que levantará un nuevo Uruguay. Aquí está el pueblo, que no ha perdido la fe ni en si mismo ni en el destino del país. Nunca se abrió un cauce tan ancho para la unidad popular como en estos momentos. Nunca, salvo con Artigas. También junto a él el pueblo oriental se unió, para enfrentar a la oligarquía y al imperialismo de la época. Y hoy volvemos a lo mismo. Por eso el pueblo, por eso el Frente Amplio es el legítimo heredero de la tradición artiguista y toma sus banderas y su ideario. Y no es que cada ciudadano, que cada grupo o partido pierda u olvide sus tradiciones partidarias. Las guarda y las cuida celosamente, porque esas tradiciones sirvieron para construir el Uruguay, pero las integra y las une en un sólo haz, porque la fuerza del Frente Amplio está en que asume las mejores tradiciones uruguayas para construir un Uruguay mejor.

Esta moderación discursiva le permite al FA abrirse hacia el centro, reducir temores ${ }^{8}$. De hecho, al menos hasta las elecciones del 2004, la distribución del electorado frentamplista tiende a ser cada vez más centrista y menos izquierdista (Canzani, 2005). 
Lo que parece estar claro es que la izquierda, bajo las condiciones imperantes, para acceder al gobierno, ha tenido que "centrarse", lo que en cierto modo implica dejar de ser izquierda propiamente tal. La alternativa, mantener a como dé lugar las banderas tradicionales de la izquierda, implica renunciar a ser mayoría. Al menos bajo las condiciones actuales y mientras no se avizore una propuesta clara, creíble, viable, distinta a la capitalista. 


\section{Notas}

${ }^{1}$ Eran años durante los cuales en Chile el gobierno de Salvador Allende, respaldado por la coalición de izquierda llamada Unidad Popular, era acosado por una ofensiva de la derecha política y económica y que culminaría con el golpe del 73 encabezado por Pinochet.

${ }^{2}$ En el mismo año, 1980, en Chile la dictadura también convocaba a un plebiscito en torno a una propuesta de respaldo a Pinochet, para recién 10 años después iniciar un supuesto proceso de normalización. A diferencia del resultado uruguayo, en Chile el plebiscito, llevado a cabo sin padrón electoral alguno, fue ganado por Pinochet y le permitió continuar su senda.

${ }^{3}$ La diferencia radica en que al cabo de 20 años, en Uruguay el gobierno es encabezado por la izquierda, mientras que en Chile la transición terminó con un gobierno de derecha.

${ }^{4}$ Es lo que en Chile llaman las primarias, con la diferencia que en Uruguay se encuentran establecidas y normadas constitucionalmente y no tienen carácter voluntario, sino que son obligatorias.

${ }^{5}$ En estricto rigor, Tabaré es candidato no solo del FA, sino que de Encuentro Progresista (EP) y Nueva Mayoría (NM), que son otros movimientos partidarios que adhirieron a su candidatura.

${ }^{6}$ En Chile se siguió una lógica distinta a la uruguaya: mientras en Uruguay la coalición resolvió escoger un candidato con un tinte más progresista que Tabaré, en Chile se resolvió llevar un candidato más conservador que Michelle, sobre la base -mas o menos reconocidade que en esta oportunidad le "tocaba" a un demócratacristiano luego de dos presidencias de socialistas para evitar la fuga de votos de centro hacia el candidato opositor. En la práctica esta lógica no funcionó, pesando fuertemente el desgaste de una coalición con 20 años de gobierno consecutivos en el cuerpo.

${ }^{7}$ A diferencia del Uruguay, la popularidad de Michelle al término de su gobierno en Chile no fue suficiente para que la Concertación triunfara; las razones de la derrota se encuentran en pleno proceso de análisis al momento de escribir este artículo.

${ }^{8}$ Similar fenómeno al vivido en Chile desde la instalación de la Concertación en Chile. 


\section{Bibliografía}

Blixen, S. (2000), Sendic, Ed. Trilce, Montevideo, Uruguay.

Buquet, D. (2009), “Uruguay 2008: de las reformas a la competencia electoral” en Revista de Ciencia Política, vol 29 (2), Santiago-Chile, pp. 611632.

Caetano, G. (2005), Liber Seregni, Ed. Taurus, Montevideo, Uruguay.

Cafassi, E. (2010), “CONRAD: Timba con garantías”, en Diario La República de Montevideo, Uruguay, el 14/2/2010

Canzani, A. (2005), Cómo llegar a buen puerto: un análisis desde la opinión pública de la trayectoria del EPFA, en Buquet, D. (ed.) Las claves del cambio. Ciclo electoral y nuevo gobierno 2004/2005, Montevideo, Uruguay.

Corbo, D. (2006), El plebiscito constitucional de 1980, Ed. Puerta del Sur, Montevideo, Uruguay.

Gilio, M.E. (2010), Pepe Mujica de tupamaro a presidente, Ed. Le Monde Diplomatique, Montevideo, Uruguay.

Lanzaro, J. (ed) (2004), La izquierda uruguaya: entre la oposición y el gobierno, Ed. Fin de Siglo, Montevideo, Uruguay.

Lessa, A. (2003), Estado de Guerra, Ed. Fin de Siglo, Montevideo, Uruguay.

Martinez, V. (2005), Tiempos de dictadura, Eds. de la Banda Oriental, Montevideo, Uruguay.

Piñeiro, R. (2007), "El sueño de la lista propia: los dilemas de coordinación electoral post-reforma de 1997” en Revista Uruguaya de Ciencia Política, $n^{\circ}$ 16, Montevideo, Uruguay, pp. 51-71

Queirolo, R. (2006) Las elecciones uruguayas de 2004: la izquierda como la única oposición creíble en Revista Colombia Internacional, $n^{\circ} 64$, Universidad de los Andes, Colombia, pp. 34-49.

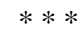

Recibido: 29.04.2010

Aceptado: 03.12.2010 